\section{Unexplained orofacial pain - is an early diagnosis possible?}

\author{
V. R. Aggarwal, ${ }^{1}$ J. McBeth, ${ }^{2}$ J. M. Zakrzewska ${ }^{3}$ and G. J. Macfarlane ${ }^{4}$ \\ VERIFIABLE CPD PAPER
}

IN BRIEF

- Allows clinicians to make an early diagnosis of unexplained orofacial pain

- Therefore helps to avoid unnecessary invasive dental treatment.

- This in turn reduces risk of medico-legal complaints.

- Appropriate referral can be made at the outset, avoiding multiple consultations.

- This can lead to improved management.

\begin{abstract}
Aim To identify distinct characteristics of unexplained orofacial pain that could be used by dental practitioners in making an early diagnosis. Methods Subjects reporting orofacial pain in a postal questionnaire-based cross-sectional survey were invited for clinical examination. The interviewer was blinded to the questionnaire responses of the subjects. A diagnosis was made following the examination and subjects were assigned into two groups: unexplained pain and dental pain. The questionnaire responses of subjects who had consulted a healthcare professional within these two groups were then compared with particular attention to demographics, orofacial pain characteristics, consultation behaviour and relationship with other unexplained syndromes. Results Subjects who had consulted for their pain and were assigned to the unexplained orofacial pain group were significantly $(p<0.05)$ more likely to report the following characteristics: pain descriptors (nagging, aching, tingling), pain pattern (worse with stress), site (poorly localised), duration (persistent/chronic), high disability, multiple consultations and co-morbidities (teeth grinding, reporting of other unexplained syndromes).
\end{abstract}

Conclusion This study has shown that unexplained orofacial pain has distinct characteristics that differentiate it from other common dental conditions. This provides a good evidence base which can reduce uncertainty among dental practitioners, allowing them to make an early diagnosis.

\section{INTRODUCTION}

Unexplained orofacial pain, also termed persistent idiopathic facial pain, includes a group of conditions, namely temporomandibular disorders, atypical facial pain, atypical odontalgia and burning mouth syndrome, which have been shown to cluster together into a single group. ${ }^{1}$ Recent studies have emphasised the difficulties faced by primary, secondary and tertiary care

${ }^{1}$ Clinical Lecturer in Primary Care Dentistry, ${ }^{2}$ Senior Lecturer in Epidemiology, Arthritis Research Campaign Epidemiology Unit, Division of Epidemiology and Health Sciences, The Medical School, University of Manchester, Oxford Road, Manchester, M13 9PT; ${ }^{3}$ Consultant in Oral Medicine, Eastman Dental Hospital, University College London Hospitals, 256 Gray's Inn Road, London, WC1X 8LD; ${ }^{4}$ Professor of Epidemiology, Aberdeen Epidemiology Group, Department of Public Health, University of Aberdeen School of Medicine, Polwarth Building, Foresterhill, Aberdeen, AB25 2ZD

${ }^{*}$ Correspondence to: Dr Vishal R. Aggarwal Email: vishal.r.aggarwal@manchester.ac.uk

\section{Online article number E6}

Refereed Paper - accepted 29 February 2008

DOI: $10.1038 /$ sj.bdj.2008.585

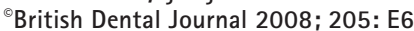

dental practitioners in diagnosing these conditions, ${ }^{2,3}$ with various terminologies used to describe conditions such as atypical facial pain. ${ }^{3}$ Previous studies have also shown that a diagnosis of unexplained orofacial pain is reached only after numerous clinicians from various specialties have seen the patient to exclude an organic cause. ${ }^{4}$ In addition, the patient will have had numerous diagnostic tests (X-rays, CT scans etc) and treatment ranging from surgery to analgesic and anti-depressant drugs. In the majority of cases, the proposed treatment has little or no effect and pain even becomes worse in some cases. ${ }^{4}$ This imposes a huge burden on already stretched healthcare resources. It is therefore imperative that unexplained orofacial pain can be diagnosed at the outset (primary dental and medical care) to differentiate it from orofacial pain conditions of known aetiology. This will ensure that patients are appropriately managed and referred to the right clinician.
We have recently ${ }^{5}$ developed and validated a classification questionnaire for identifying chronic/persistent idiopathic orofacial pain in populationbased epidemiological studies. During the development of this questionnaire, subjects with orofacial pain were interviewed and examined and this provided a unique opportunity to examine selfreported pain characteristics on subjects who have been randomly selected from the general population. However, the classification criteria were developed using all interviewed subjects including those who had not consulted for their pain and were therefore unlikely to present to dental practitioners. In addition, temporomandibular pain and burning mouth syndrome were not grouped into the idiopathic category. This is contrary to current findings. ${ }^{1}$

Therefore the aim of the current analyses was to identify a subset of subjects from our previous study ${ }^{5}$ who had consulted for their facial pain and using this cohort, identify distinct characteristics 
of unexplained orofacial pain whilst recategorising our diagnoses based on current findings. ${ }^{1}$ Specific objectives were (i) to identify descriptors, pattern and severity for unexplained orofacial pain and (ii) to identify co-morbidities associated with unexplained orofacial pain.

\section{METHODS}

\section{Study design and participants}

The methods of the study have been discussed in detail in the manuscript relating to the development of the epidemiological classification tool. ${ }^{5}$ Briefly, subjects with facial pain were identified by postal questionnaire responses from a population-based cross-sectional survey of 4,200 randomly selected adults registered with a general medical practice in Northwest England. Ethical approval was obtained from Macclesfield Research Ethics Committee, East Cheshire NHS Trust.

The questionnaire included a section on facial pain and those subjects who affirmed to having pain in the face, mouth or jaws which had been present for a day or longer in the past month were recruited for examination by one of the authors (VA), who was blinded to their questionnaire responses. The questionnaire appears as appendix 2 in a previously published thesis. ${ }^{6}$ The examiner was previously trained by a facial pain expert (JMZ - author) in diagnosis, and inter-operator reliability had been established in a previous pilot study. $^{7}$

A diagnosis was made at clinical examination (Table 1) for all facial pains. Headaches, which were diagnosed in a minority of subjects, were excluded as these rarely present to dental practitioners. Unexplained orofacial pain conditions were defined according to a diagnosis of temporomandibular pain, burning mouth syndrome and idiopathic orofacial pain, which is also referred to as atypical facial pain. These conditions were grouped together into an 'unexplained' group based on recent findings, ${ }^{1}$ whilst commonly encountered dental pains were grouped into a 'dental' group. Only those who had consulted for their pain were included in the analysis.

Prior to being examined, subjects completed a questionnaire that made an in-depth inquiry into their facial pain characteristics and related co-morbidities as follows:

\section{Duration}

- 'Current' orofacial pain was defined as pain during the past month in the face, mouth or jaws which has lasted for one day or longer

- Persistent pain was defined as pain that began more than three months ago.

\section{Site}

This was measured by specific questions on whether the pain was unilateral or bilateral. Specific site was measured using blank manikins of the mouth and face and examining the distribution and number of sites shaded.

\section{Pain severity}

This was measured using a visual analogue scale (VAS) for intensity, and a disability scale ${ }^{8}$ for levels of pain-associated disability. Scores of 0-3 on the VAS indicated low intensity whilst 4-10 represented high intensity. The corresponding disability scores were 0-3 (low levels) and 4-31 (high levels).

\section{Consultation behaviour}

This was measured by a 'Yes/No' question of whether participants had sought advice for their pain. If they affirmed to this, they were further asked to indicate, from a list of healthcare workers, whom they had consulted. Consultation was thus measured by the number of healthcare workers seen for pain. The list included dentist, general practitioner, hospital consultant, pharmacist, homeopath/alternative therapist and 'other'.

\section{Pain descriptors and pattern}

A short-form McGill pain questionnaire ${ }^{9}$ was used to identify descriptors associated with pain. A series of 17 'Yes/No' questions on pain pattern and associated symptoms was also included by modifying a questionnaire previously developed by Hapak et al. ${ }^{10}$

\section{Comorbidities}

These were measured in the orofacial region using 'Yes/No' questions on

\begin{tabular}{|c|c|}
\hline Diagnosis & n (\%) \\
\hline Dental pains & $52(43)$ \\
\hline Recurrent oral ulceration & $5(9)$ \\
\hline Lichen planus & $2(3)$ \\
\hline Periodontal disease & $4(7)$ \\
\hline Chronic pulpitis & $17(29)$ \\
\hline Reversible pulpitis & $1(2)$ \\
\hline Apical periodontitis & $2(3)$ \\
\hline Sinusitis & $9(15)$ \\
\hline Dry socket & $1(2)$ \\
\hline Dentine sensitivity & $4(7)$ \\
\hline Pericoronitis & $6(10)$ \\
\hline $\begin{array}{l}\text { Trauma to tissues caused by } \\
\text { dentures }\end{array}$ & $1(2)$ \\
\hline Unexplained pains & $69(57)$ \\
\hline Idiopathic orofacial pain & $49(71)$ \\
\hline Burning mouth syndrome & $1(1)$ \\
\hline Temporomandibular joint pain & $19(28)$ \\
\hline Total & $121(100)$ \\
\hline
\end{tabular}

facial trauma and teeth grinding. The questionnaire also included questions on bodily pain syndromes and fatigue including chronic widespread pain, ${ }^{11}$ irritable bowel syndrome (Rome II criteria) $)^{12}$ and chronic fatigue. ${ }^{13}$

\section{Statistical analysis}

The sample used for analysis included only those subjects who had consulted for their pain. Chi-square tests for statistical significance ( $p<0.05)$ were used to compare the differences in proportion of subjects reporting questionnaire variables between the unexplained and dental groups. Wilcoxon rank sum tests were used to compare differences in medians. All analysis were carried out using STATA version $8 .^{14}$ 


\begin{tabular}{|c|c|c|c|}
\hline & $\begin{array}{l}\text { Dental } \\
\text { n (\%) }\end{array}$ & $\begin{array}{l}\text { Unexplained } \\
\text { n (\%) }\end{array}$ & $\chi^{2} p$ value \\
\hline \multicolumn{4}{|l|}{ Number of sites of OFP } \\
\hline $1-3$ & $23(44)$ & $20(29)$ & \multirow{3}{*}{0.209} \\
\hline $4-5$ & $16(31)$ & $25(36)$ & \\
\hline 6 or more & $13(25)$ & $24(35)$ & \\
\hline \multicolumn{4}{|l|}{ Intensity (VAS scale) } \\
\hline Low (0-3) & $12(23)$ & $16(23)$ & \multirow{2}{*}{1.00} \\
\hline High (4-10) & $39(77)$ & $52(77)$ & \\
\hline \multicolumn{4}{|l|}{ Disability } \\
\hline Low (0-3) & $37(71)$ & $27(39)$ & \multirow{2}{*}{$<0.01$} \\
\hline High (3-31) & $15(29)$ & $42(61)$ & \\
\hline $\begin{array}{l}\text { Physical median } \\
(\text { IQR)\# }\end{array}$ & $0(0-1)$ & $1(0-2)$ & $0.072^{*}$ \\
\hline $\begin{array}{l}\text { Psychological median } \\
\text { (IQR) }\end{array}$ & $1(0-2)$ & $2(1-5)$ & $<0.01^{*}$ \\
\hline
\end{tabular}

"Wilcoxon rank sum test; "inter quartile range

\begin{tabular}{|c|c|c|c|}
\hline Character of OFP & $\begin{array}{l}\text { Dental } \\
\mathrm{n}(\%)\end{array}$ & $\begin{array}{l}\text { Unexplained } \\
\mathrm{n}(\%)\end{array}$ & $\chi^{2} \mathrm{p}$ value \\
\hline Throbbing & $26(50)$ & $17(25)$ & 0.004 \\
\hline Shooting & $11(21)$ & $10(15)$ & 0.338 \\
\hline Stabbing & $3(6)$ & $9(13)$ & 0.185 \\
\hline Sharp & $13(25)$ & $13(19)$ & 0.414 \\
\hline Gnawing & $13(25)$ & $11(16)$ & 0.216 \\
\hline Burning/hot & $5(10)$ & $10(15)$ & 0.420 \\
\hline Tingling & $0(0)$ & $10(15)$ & 0.004 \\
\hline Aching & $17(33)$ & $43(62)$ & 0.001 \\
\hline Tender & $17(33)$ & $25(36)$ & 0.686 \\
\hline Tiring & $7(14)$ & $12(17)$ & 0.556 \\
\hline Frightful & $1(2)$ & $5(7)$ & 0.182 \\
\hline Vicious & $3(6)$ & $7(10)$ & 0.387 \\
\hline Miserable & $9(17)$ & $20(29)$ & 0.136 \\
\hline Unbearable & $8(15)$ & $13(19)$ & 0.619 \\
\hline Nagging & $10(19)$ & $28(41)$ & 0.012 \\
\hline
\end{tabular}

\section{RESULTS}

\section{Interview response rates and group membership}

The interview response rates have been described in detail elsewhere. ${ }^{5}$ Briefly, of those with facial pain $(n=299(12 \%)), 224$
(75\%) consented to further contact and were invited for examination. Of these, 197 (88\%) were examined and questionnaire data was available for 194 (99\%). However, headache pain was reported by 12 subjects (migraine $\mathrm{n}=10$ and chronic tension headache $\mathrm{n}=2$ ), one subject reported more than one type of pain, while six subjects reported neuralgic pain (trigeminal neuralgia, glossopharyngeal neuralgia and atypical trigeminal neuralgia). These subjects were excluded. of the remaining 175, 121 (69\%) had consulted for their facial pain and this was the sample used for analysis.

Of this sample, 69 (57\%) subjects were assigned into the unexplained pain group based on their diagnoses (Table 1) while 52 (43\%) were assigned to the dental group.

\section{Characteristics of unexplained orofacial pain}

\section{Demographics, severity,} descriptors and pattern

Subjects with unexplained orofacial pain were older (16\% vs 10\%) and a higher proportion were female $(73 \%$ vs $62 \%$ ), although the differences were not statistically significant ( $p>0.05$ ). Subjects with unexplained orofacial pain were also significantly ( $p<0.05)$ more likely to report higher levels of overall disability, in particular psychosocial disability (Table 2).

Pain descriptors more likely to be reported by subjects with unexplained orofacial pain were aching, nagging and tingling pain which was less likely to be throbbing (Table 3).

Unexplained orofacial pain was more likely, compared to dental pain, to be worse when subjects were stressed and it was more likely to be poorly localised, ie bilateral pain and pain at multiple sites (Tables 2 and 4). In addition, unexplained pain was less likely than dental pain to arise from the teeth or start on eating hot/cold foods (Table 4).

\section{Co-morbidities and consultation behaviour}

The proportion of subjects who had consulted a healthcare worker other than their dentist was much higher for subjects with unexplained pain (Table 5). Although the proportion of subjects who had consulted any healthcare worker was similar for both dental and unexplained pains, subjects with unexplained pain were significantly ( $p<0.05)$ more likely to have consulted multiple healthcare workers (Table 5). 


\begin{tabular}{|c|c|c|c|}
\hline Pattern of OFP & $\begin{array}{l}\text { Dental } \\
\mathrm{n}(\%)\end{array}$ & $\begin{array}{l}\text { Unexplained } \\
\mathrm{n}(\%)\end{array}$ & $\chi^{2} \mathrm{p}$ value \\
\hline Constant & $5(10)$ & $6(9)$ & 0.808 \\
\hline Intermittent & $25(50)$ & $36(52)$ & 0.815 \\
\hline Clusters & $8(16)$ & $15(22)$ & 0.434 \\
\hline Worse & $6(12)$ & $8(12)$ & 0.946 \\
\hline On skin & $0(0)$ & $4(6)$ & 0.083 \\
\hline From teeth & $30(60)$ & $16(23)$ & $<0.001$ \\
\hline Either side & $8(16)$ & $17(25)$ & 0.254 \\
\hline Bilateral & $2(4)$ & $16(23)$ & 0.004 \\
\hline Begins on touch & $1(2)$ & $2(3)$ & 0.758 \\
\hline Begins with hot/cold & $14(28)$ & $6(9)$ & 0.005 \\
\hline Worse with stress & $4(8)$ & $25(36)$ & $<0.001$ \\
\hline Worse by moving jaw & $14(28)$ & $25(36)$ & 0.345 \\
\hline $\begin{array}{l}\text { Worse bending } \\
\text { forwards }\end{array}$ & $6(12)$ & $9(13)$ & 0.866 \\
\hline Better heat/cold & $2(4)$ & $7(10)$ & 0.211 \\
\hline Running nose & $4(8)$ & $2(3)$ & 0.209 \\
\hline Red/watery eyes & $3(6)$ & $2(3)$ & 0.405 \\
\hline
\end{tabular}

Table 5 Consultation behaviour among orofacial pain groups

\begin{tabular}{|c|c|c|c|}
\hline & $\begin{array}{l}\text { Dental } \\
\text { n (\%) }\end{array}$ & $\begin{array}{l}\text { Unexplained } \\
\mathrm{n}(\%)\end{array}$ & $\chi^{2} \mathrm{p}$ value \\
\hline \multicolumn{4}{|c|}{ Healthcare worker consulted } \\
\hline Dentist & $36(69)$ & $37(53)$ & 0.082 \\
\hline General practitioner & $15(29)$ & $41(59)$ & 0.001 \\
\hline Hospital consultant & $8(15)$ & $26(38)$ & 0.007 \\
\hline Pharmacist & $1(2)$ & $5(7)$ & 0.182 \\
\hline Alternative therapist & $0(0)$ & $6(9)$ & 0.029 \\
\hline Other & $0(0)$ & $5(7)$ & 0.047 \\
\hline \multicolumn{4}{|l|}{ Number consulted } \\
\hline 1 & $44(85)$ & $36(52)$ & \\
\hline 2 & $8(15)$ & $19(28)$ & \\
\hline 3 & $0(0)$ & $11(16)$ & 0.002 \\
\hline 4 & $0(0)$ & $2(3)$ & \\
\hline 5 & $0(0)$ & $1(2)$ & \\
\hline
\end{tabular}

In addition, subjects with unexplained pain were more likely to report grinding of their teeth which had been verified by their dentist or family member (Table 6). Although not statistically significant, the proportion of subjects with unexplained pain who reported facial trauma was also higher (Table 6).

Finally, subjects with unexplained pain were more likely to report having chronic pain and multiple unexplained syndromes (Tables 7a and 7b).

\section{DISCUSSION}

This study has shown that unexplained orofacial pain has distinct characteristics that differentiate it from other common dental conditions. In particular were aspects of pain descriptors, pattern, severity, associated co-morbidities and consultation behaviour, which can help reduce uncertainty among dental practitioners allowing them to make an early diagnosis.

The main strength of the current study derives from its population-based setting, which allowed us to encompass a whole range of cases of unexplained orofacial pain. Furthermore, because the interviewer was blinded to the questionnaire responses of the subjects, we are likely to have eliminated interviewer bias and therefore the responses are likely to reflect areas that are important to patients suffering from orofacial pain.

Pain descriptors are particularly useful in diagnosing pain, for example the electric nature of trigeminal neuralgia and the pulsating, throbbing pain of chronic pulpitis. ${ }^{15,16}$ Similarly, unexplained orofacial pain was found to have a 'nagging', 'aching' and 'tingling' description. However, there are methodological issues that warrant consideration. Although nagging, aching and tingling were significantly associated with unexplained orofacial pain, there were other descriptors that should not be ignored, although they were not statistically significant. These include 'burning' and 'frightful', which were reported by a higher proportion of subjects with unexplained orofacial pain and may be important in diagnosis. Further research is required into the importance of these descriptors for diagnosing unexplained orofacial pain. 


\begin{tabular}{|c|c|c|c|}
\hline Oral health factors & $\begin{array}{l}\text { Dental } \\
\mathrm{n}(\%)\end{array}$ & $\begin{array}{l}\text { Unexplained } \\
\text { n (\%) }\end{array}$ & $\chi^{2} p$ value \\
\hline Dental registration & $50(96)$ & $63(93)$ & 0.417 \\
\hline Check-ups & $46(89)$ & $60(87)$ & 0.804 \\
\hline Grind teeth & $12(23)$ & $27(40)$ & 0.054 \\
\hline Verified grinding & $10(19)$ & $26(38)$ & 0.028 \\
\hline Teeth fit & $17(34)$ & $28(44)$ & 0.291 \\
\hline Teeth missing & $35(67)$ & $53(77)$ & 0.245 \\
\hline Facial trauma & $12(23)$ & $22(34)$ & 0.202 \\
\hline
\end{tabular}

\begin{tabular}{|c|c|c|c|}
\hline Symptoms* & $\begin{array}{l}\text { Dental } \\
\text { n (\%) }\end{array}$ & $\begin{array}{l}\text { Unexplained } \\
\mathrm{n}(\%)\end{array}$ & $\chi^{2} p$ value \\
\hline COFP & $27(53)$ & $55(81)$ & 0.001 \\
\hline CWP & $10(20)$ & $32(48)$ & 0.002 \\
\hline IBS & $10(20)$ & $21(31)$ & 0.169 \\
\hline $\mathrm{CF}$ & $11(22)$ & $23(33)$ & 0.157 \\
\hline
\end{tabular}

Table 7b Distribution of orofacial pain (OFP) groups by number of symptoms reported

\begin{tabular}{|l|l|l|l|}
\cline { 1 - 2 } Number of symptoms & $\begin{array}{l}\text { Dental } \\
\mathrm{n}(\%)\end{array}$ & $\begin{array}{l}\text { Unexplained } \\
\mathrm{n}(\%)\end{array}$ & \multirow{2}{*}{0.007} \\
\cline { 1 - 3 } & $24(50)$ & $26(40)$ & \\
\hline 1 & $18(38)$ & $14(22)$ & \\
\hline 2 & $6(13)$ & $15(23)$ & \\
\hline 3 & $0(0)$ & $10(15)$ & \\
\hline
\end{tabular}

Pain severity measures indicated higher disability scores, in particular psychosocial disability, and this correlates well with the persistent nature of unexplained orofacial pain and findings from clinic studies, which indicate higher levels of psychological distress in patients with unexplained pain. ${ }^{17}$

Dental pain, particularly cariesrelated toothache, is well localised and in contrast, unexplained orofacial pain was found to be poorly localised, with subjects not only reporting pain at distinguishing unexplained orofacial pain from other common dental pains.

Aspects of consultation behaviour were as expected. Those with dental pain had a higher proportion who had consulted a dentist, while those with unexplained pain had higher proportions that had consulted other healthcare workers. Importantly, those with unexplained orofacial pain were more likely to have consulted a larger number of healthcare workers. This emphasises the burden of unexplained orofacial pain conditions on already overstretched healthcare resources and the importance of early diagnosis. This finding is supported by several studies ${ }^{4,22,23}$ and is a characteristic of subjects presenting with unexplained pain conditions to any medical specialty.

Co-morbid pain symptoms were more likely for unexplained orofacial pain subjects and this finding has been replicated in tertiary ${ }^{18,21,24}$ and primary care. ${ }^{25}$ Further, a recent case control study has shown a significant association between long-term back pain and musculoskeletal disrders of the jaw. ${ }^{26}$ Subjects with unexplained orofacial pain were also more likely to report grinding of their teeth which had been verified by a family member or the dentist. This co-morbidity is often reported in clinical settings and has been recently shown to be non-specific to orofacial pain and may indeed be a feature of somatisation. ${ }^{27}$ It is therefore crucial that dentists enquire about other bodily pain. This study showed that selfreported mechanical factors like tooth grinding that are known to be associated with unexplained orofacial pain are also associated with other unexplained syndromes and therefore may represent a heightened awareness of bodily symptoms generally. This is a further indication that such unexplained conditions are not associated with underlying dental organic pathology and the use of extensive invasive therapy such as occlusal adjustments and splints to change mechanical factors may not be justified in many cases - a view also supported by recent systematic reviews. ${ }^{28,29}$

Overall, therefore, the current study has provided a good evidence base, using which an early diagnosis of unexplained orofacial pain can be achieved. Clinical 
characteristics of this condition include pain descriptors (nagging, aching, tingling), pain pattern (worse with stress), site (poorly localised), duration (persistent/chronic), high disability, multiple consultations and co-morbidities (teeth grinding, reporting of other unexplained syndromes). It is therefore essential that all patients are managed holistically and that a thorough history, clinical and radiographic examination is carried out which includes details of pain descriptors, pattern, severity, co-morbidities and consultation behaviour. If this approach fails to reveal an underlying dental cause then it is possible that the patient may have unexplained orofacial pain and appropriate referral should be instigated. Understandably, this can take substantial time, which can appear in the short-term to incur financial penalties under the new contract. However, initiating treatment which is unsupported by clinical and radiographic examination can incur medico-legal problems and much time will be wasted, in the long-term, getting the patient back for multiple procedures which do not improve symptoms. The number of secondary care consultations can also be reduced as patients search for a diagnosis and then treatment.

The authors are most grateful to staff/patients of The Handforth Health Centre and Handforth Clinic for their help with the study. V. R.

Aggarwal was supported by a Wellcome Trust Fellowship in clinical epidemiology (066863) Z/02/Z) which funded the study.
1. Woda A, Tubert-Jeannin S, Bouhassira Det al. Towards a new taxonomy of idiopathic orofacial pain. Pain 2005; 116: 396-406.

2. Durham J, Exley C, Wassell R, Steele J G. 'Management is a black art' - professional ideologies with respect to temporomandibular disorders. Br Dent J 2007: 202: E29.

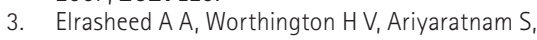
Duxbury A J. Opinions of UK specialists about terminology, diagnosis, and treatment of atypical facial pain: a survey. Br J Oral Maxillofac Surg 2004; 42: 566-571.

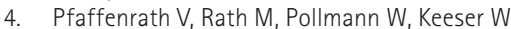
Atypical facial pain - application of the IHS criteria in a clinical sample. Cephalalgia 1993; 13 (Suppl 12): $84-88$

5. Aggarwal V R, McBeth J, Lunt M, Zakrzewska J M, Macfarlane G J. Development and validation of classification criteria for idiopathic orofacial pain for use in population-based studies. J Orofac Pain 2007; 21: 203-215.

6. Aggarwal VR K. Epidemiology of chronic orofacial pain. Manchester: University of Manchester, 2006 Thesis.

7. Macfarlane T V, Blinkhorn A S, Craven R et al. Can one predict the likely specific orofacial pain syndrome from a self-completed questionnaire? Pain 2004; 111: 270-277.

8. Aggarwal V R, Lunt M, Zakrzewska J M, Macfarlane G J, Macfarlane TV. Development and validation of the Manchester orofacial pain disability scale. Community Dent Oral Epidemiol 2005; 33: 141-149.

9. Melzack R. The short-form McGill Pain Questionnaire. Pain 1987: 30: 191-197.

10. Hapak L, Gordon A, Locker D, Shandling M, Mock $D$, Tenenbaum H C. Differentiation between musculoligamentous, dentoalveolar, and neurologically based craniofacial pain with a diagnostic questionnaire. J Orofac Pain 1994; 8: 357-368.

11. Wolfe F, Smythe H A, Yunus M B et al. The American College of Rheumatology 1990 criteria for the classification of fibromyalgia. Report of the multicenter criteria committee. Arthritis Rheum 1990; 33: 160-172.

12. Thompson $W G$, Longstreth $G F$, Drossman $D A$, Heaton K W, Irvine E J, Muller-Lissner S A. Functional bowel disorders and functional abdominal pain. Gut 1999; 45 (Suppl 2): ||43-||47.

13. Chalder T, Berelowitz G, Pawlikowska T et al. Development of a fatigue scale. J Psychosom Res 1993; 37: 147-153.

14. Stata [computer program]. Version Release 8.0. College Station, TX: Stata Corporation, 2003.
15. Zakrzewska J M, Harrison S D. Assessment and management of orofacial pain. Amsterdam; London: Elsevier, 2002.

16. McNeill C, Dubner R. What is pain and how do we classify orofacial pain? In Lund J P, Lavigne G J, Dubner R, Sessle B J (eds) Orofacial pain: from basic science to clinical management. pp 3-14. Chicago; London: Quintessence, 2001.

17. Feinmann C, Harrison S. Liaison psychiatry and psychology in dentistry. J Psychosom Res 1997; 43: 467-476.

18. Feinmann C, Harris M. Psychogenic facial pain. Part 1: the clinical presentation. Br Dent J 1984; 156: $165-168$.

19. Newton-John T, Madland G, Feinmann C. Chronic idiopathic orofacial pain: II. What can the general dental practitioner do? Br Dent J 2001 191: 72-73.

20. International classification of headache disorders 2nd edition. Cephalalgia 2004; 24(s1): 23-136.

21. Madland G, Newton-John T, Feinmann C. Chronic idiopathic orofacial pain: I. What is the evidence base? Br Dent J 2001; 191: 22-24.

22. Madland G, Feinmann C. Chronic facial pain: a multidisciplinary problem. J Neurol Neurosurg Psychiatry 2001; 71: 716-719.

23. Feinmann C, Harris M, Cawley R. Psychogenic facial pain: presentation and treatment. Br Med J (Clin Res Ed) 1984; 288: 436-438.

24. Feinmann $\mathrm{C}$, Harris M. The diagnosis and management of psychogenic facial pain disorders. Clin Otolaryngol 1984; 9: 199-201.

25. Aggarwal V R, McBeth J, Zakrzewska J M, Lunt M, Macfarlane $G J$ J. The epidemiology of chronic syndromes that are frequently unexplained: do they have common associated factors? Int J Epidemiol 2006: 35: 468-476.

26. Wiesinger $B$, Malker $H$, Englund $E$, Wanman A. Back pain in relation to musculoskeletal disorders in the jaw-face: a matched case-control study. Pain 2007: 131: 311-319.

27. Aggarwal V R, McBeth J, Zakrzewska J M, Lunt $M$, Macfarlane G J. Are reports of mechanical dysfunction in chronic orofacial pain related to somatisation? A population based study. Eur J Pain 2008; 12: 501-507

28. Al-Ani Z, Gray R J, Davies S J, Sloan P, Glenny A M. Stabilization splint therapy for the treatment of temporomandibular myofascial pain: a systematic review. J Dent Educ 2005; 69: 1242-1250.

29. Koh H, Robinson P G. Occlusal adjustment for treating and preventing temporomandibular joint disorders. J Oral Rehabil 2004; 31: 287-292. 